\title{
REFLEXIÓN SOBRE EL PAPEL DOCENTE Y LAS ESTRATEGIAS DE ENSEÑANZA EN NUESTRO SISTEMA EDUCATIVO PERUANO
}

\author{
Patricia Fernández Calderón
}

\begin{abstract}
RESUMEN
El docente cumple un rol muy importante dentro de la educación peruana. Es el que lleva la mayor responsabilidad en cuanto al desarrollo del proceso de enseñanza y aprendizaje en los alumnos. Por ello, debe contar con una serie de estrategias que le permitan mejorar su trabajo en las aulas para cumplir con las exigencias de la sociedad y el mundo globalizado.
\end{abstract}

Este artículo es una reflexión sobre cómo se desenvuelve el maestro en nuestro sistema educativo y cuáles son sus nuevos desafíos.

\section{PALABRAS CLAVE}

Sistema educativo, estrategias de enseñanza, procesos de aprendizaje, procesos cognitivos, innovación.

\section{ABSTRACT}

The teacher plays a very important role in Peruvian education. It is the one with the greatest responsibility for the development of the teaching and learning process in the students. Therefore, it must have a series of strategies that allow it to improve its work in classrooms to meet the demands of society and the global world.

This article is a reflection on how the teacher works in our educational system and what the new challenges are.

\section{KEYWORDS}

Educational system, teaching strategies, learning processes, cognitive processes, innovation.
$\mathrm{D}$ urante las últimas décadas, nos hemos visto beneficiados con los descubrimientos y avances tecnológicos y científicos que el mundo globalizado nos ha permitido asimilar; sin embargo, esto no ha garantizado un progreso y desarrollo social. En el Perú, nuestra situación se ha ido agudizando por diversos problemas como la injusticia, la corrupción, la violencia, la inseguridad ciudadana y la influencia negativa de los medios de comunicación en nuestros niños y jóvenes.

Esto nos lleva a reflexionar sobre la función que ha venido cumpliendo la educación con respecto al desarrollo de nuestro país y, por consiguiente, sobre la responsabilidad que recae en nuestro sistema educativo la formación de las nuevas generaciones, sabiendo cómo nos encontramos hoy en día. En ese sentido, la sociedad actual exige nuevas competencias personales, profesionales y sociales que permitan afrontar esta realidad.

Entre el 2002 y 2005, la educación peruana mostró ligeras mejoras en algunos indicadores, tales como la disminución en las tasas de deserción y repetición; pero quizás el avance más importante esté en las diversas iniciativas orientadas a promover estándares educativos, los cuales tienen por objetivo establecer metas de aprendizaje que guíen y articulen el sistema, de tal forma que favorezca la calidad educativa en todos los centros educativos del país.

La implementación de las rutas de aprendizaje que se hizo en el año 2013 fue, quizás un gran aporte para los maestros en su trabajo pedagógico en las aulas; ya que, tuvo como finalidad dar sugerencias didácticas para la enseñanza de los aprendizajes fundamentales y alcanzar los estándares establecidos en los mapas de progreso al fin de cada ciclo; sobre todo, demandó la presencia de un docente que asuma de manera plena, la responsabilidad de formar a futuros 
ciudadanos comprometidos con el desarrollo de supaís.

En este caso, las rutas de aprendizaje permitieron a los docentes hacer una reflexión y a la vez una crítica acerca de su trabajo pedagógico en las aulas, sobre todo al momento de elaborar sus sesiones de aprendizaje, teniendo en cuenta los procesos de aprendizaje del alumno y quizás esta sea la parte más complicada para el trabajo docente porque implica conocer también los procesos cognitivos del estudiante.

Hoy más que nunca, las posibilidades de comprender, analizar, sintetizar y evaluar el cúmulo de información que llega a los jóvenes parecen casi imposibles. Sin embargo, esa es una de las metas que persigue el educador reflexivo, aquel que busca que sus alumnos no sólo se incorporen con éxito al mercado laboral, sino que adquieran una sólida formación, un método de aprendizaje y una disposición hacia la creatividad y el pensamiento crítico.

Según Parra (2010), el actual ejercicio docente en gran parte de las instituciones educativas (educación formal y no formal) se caracteriza por desarrollar los procesos de enseñanza y aprendizaje con la estrategia de enseñanza expositiva (clase magistral) y/o enseñanza tradicional, conllevando en muchos casos a que los procesos educativos se conviertan en simples procesos de trasmisión de conocimientos favoreciendo con esto, la dependencia intelectual de los autores de textos y/o docentes y limitando procesos como la creatividad, la solución de problemas y la investigación.

Esta afirmación de alguna manera se ve reflejada con los últimos resultados arrojados a nivel mundial por la Prueba Pisa en el año 2012, donde quedamos en el último lugar en comprensión lectora, matemáticas y ciencias. Lo mismo pasa con la última evaluación censal a los alumnos del segundo de secundaria en el 2015 a nivel nacional con resultados bajos en comprensión lectora y matemáticas. Es así que somos testigos de que algo pasa en las aulas peruanas en cuanto a la enseñanza que se imparte y el aprendizaje que adquieren los alumnos. Por ello, es necesario un gran cambio que mueva las bases de nuestro sistema educativo y que apuesten por una verdadera innovación que mejore la calidad de enseñanza para el beneficio de nuestros estudiantes.

Robinson (citado por Trahtemberg 2016: parr.1) en su conferencia "Cómo escapar del valle de la muerte de la educación", sostiene que los sistemas educativos fracasan porque no entienden los tres principios esenciales de la naturaleza humana que son:

1) Los individuos son diferentes, pese a lo cual los colegios se orientan a la conformidad, mirándolos desde un estrecho espectro de logros prioritarios (matemáticas, lengua, ciencia, que son importantes, pero no suficientes porque dejan fuera el arte, humanidades, educación física, etc.). Los niños avanzan mejor con currículos y estrategias pedagógicas diversas que hagan aflorar sus capacidades.

2) Los individuos son curiosos, son aprendices naturales, pero eso choca con una docencia dedicada a entregar información más que a crearla. Los grandes profesores son mentores que estimulan, empoderan, alientan, provocan, para producir aprendizajes, sin los cuales no hay educación. El rol del profesor es facilitar el aprendizaje, pero para ello tiene que encender el motor de la curiosidad de los niños lo cual es contradictorio con la tarea de evaluarlos continuamente para asegurar que alcancen los estándares pre establecidos.

Los tests obstaculizan el aprendizaje en lugar de facilitarlo. La curiosidad se frena, si se la reemplaza por la complacencia.

3) La mente humana es inherentemente creativa: imagina opciones y crea alternativas. La tarea de la educación debe ser despertar los poderes de la creatividad.

En su lugar, tenemos en América una cultura de estandarización, frente a la de los países nórdicos que se enfocan en 
individualizar la enseñanza, moldearla en función de cada alumno, para lo cual contratan profesores de altísimo nivel de formación, capacitación continua y reconocimiento social. Le dan a la escuela la responsabilidad de hacer su trabajo sin el comando y control externo (ministerial) de lo que hace cada maestro o escuela. Se alejan de las concepciones mecanicistas de la educación conceptualizada como proceso industrial para entenderlo como un proceso humano en el que interactúan personas con sus propias características y biografías.

Más allá de la crítica que se hace a los sistemas educativos tradicionales, lo más importante es que reconocemos en estos principios la importancia del rol docente y su trabajo pedagógico frente a la naturaleza de los estudiantes. Sobre todo, que todos sus esfuerzos están enfocados en el desarrollo de capacidades a través de estrategias de enseñanza que se centren en la individualidad del alumno.

Como sabemos, las estrategias de enseñanza se conciben como los procedimientos utilizados por el docente para promover aprendizajes significativos que implican actividades conscientes y orientadas a un fin. Según Beltrán (1999), el adecuado y consciente uso de las estrategias, conllevan a una "instrucción estratégica interactiva" y de alta calidad. Por ello, el instructor estratégico debe ser un verdadero mediador, y un modelo para el alumno. El docente debe dirigir su acción a influir en los procesos de aprendizaje de los alumnos.

Ahora, seleccionar las estrategias adecuadas para lograr una capacidad requiere analizar la demanda cognitiva de ésta; es decir, a qué nivel de pensamiento corresponde, cuáles son las tareas que se espera que los estudiantes realicen, así como los procesos cognitivos que se deben seguir para ejecutarla. Debemos elaborar sesiones de clase que respondan a las siguientes preguntas: ¿Qué propósito buscamos en cada clase? ¿Qué deben aprender nuestros estudiantes? ¿A qué actividad le damos mayor tiempo en clase: a las explicaciones o al trabajo de los estudiantes?

La realidad es que los resultados de las evaluaciones en nuestras aulas, así como las censales a nivel nacional y las internacionales del tipo Pisa, nos indican que la mayoría de nuestros estudiantes están acostumbrados a repetir información, pero sin comprender el porqué de ella. Tampoco conocen cuándo deben aplicarla para resolver problemas, sean académicos o de situaciones cotidianas; no logran conectar el saber con esta realidad.

Por ello, el gran desafío de los docentes no es solo seleccionar las estrategias adecuadas, sino es comprender el propósito de la capacidad, su nivel de pensamiento, las tareas según la demanda cognitiva y los procesos cognitivos que se deben seguir para ejecutarla. Sobre todo, que se promueva un aprendizaje basado en un procesamiento profundo de la información, en donde se emplee preguntas, ejercicios, ejemplos, explicaciones alternativas, y en general presente actividades donde el alumno analice, reflexione, realice actividades interesantes y novedosas. Sobre todo, que se ponga énfasis en el uso de las Tics donde el estudiante se involucre activamente en su aprendizaje.

Además, Díaz y Hernández (1999) dentro de sus lineamientos generales para el empleo de las estrategias de la enseñanza, nos indican que es importante ofrecer al alumno la información suficiente acerca de lo que se espera de su participación en el curso o clase e intercambiar puntos de vista con el fin de fomentar su interés y participación.

Lo mismo afirma Diaz (2012), cuando nos dice que en estudios realizados sobre la enseñanza afectiva, que se caracteriza por las relaciones positivas, cercanas y de afecto entre profesor y alumno, el aprendizaje cognitivo y los niveles de atención en clase mejoran.

Según Amegan (2000), los maestros deberíamos esperar del alumno resultados nuevos, diferentes y únicos; y planearlo todo para que eso sea posible; además, podemos estimular el pensamiento divergente, en otras palabras, la manera de enfrentar viejos y nuevos problemas con ideas nuevas, perspicaces, ingeniosas y, justamente, creativas. El maestro debe promover conocimientos, pero también prever la utilización de dichos conocimientos en situaciones de resolución de problemas. En suma, debe fomentar a través de su trabajo en el aula, el pensamiento creativo de sus alumnos.

Finalmente, López (2013) nos indica que la misión 
de la escuela no es tanto enseñar al alumno una multitud de conocimientos, sino ante todo, procurar que el alumno llegue a adquirir una autonomía intelectual. La importancia de la formación del pensamiento crítico se basa en la necesidad de los alumnos en cómo se enfrentará a los retos de la vida por medio de la reflexión y el razonamiento.

Para concluir, el mundo globalizado y nuestra situación social nos están proponiendo nuevos retos como docentes en nuestro quehacer educativo, en donde no perdamos nuestro continuo crecimiento profesional, involucrarnos más en las tecnologías de la información y que nos mantengamos alerta a las necesidades de nuestros alumnos. Así, procuraremos una formación integral, que esté dirigida a que los alumnos aprendan a conocer, aprendan a hacer, aprendan a convivir y aprendan a ser. Todo esto por medio de actividades vivenciales que pongan a los chicos a enfrentar situaciones reales, en aprendizajes basados en problemas, con el propósito de alcanzar competencias y aprendizajes que los lleven a enfrentar efectivamente situaciones de su vida diaria.

Todo lo mencionado anteriormente, es un reto que en gran medida tendrá dificultades, pero que, sin duda, no será imposible de alcanzar, teniendo presente el deber con el que se requiere asumir la responsabilidad de la importancia social que implica, ser maestro.

\section{REFERENCIAS}

Amegan, S. (2000). Para una pedagogía activa y creativa. México: Trillas.

Beltrán, P. (1999). Estrategias de enseñanza en el aula. México: Trillas.

Diaz, L. (2012). Losvínculos de cercanía en el ejercicio de la tutoría del CCH Naucalpan. Tesis de Maestría. Facultad de Ciencias Políticas. UNAM.

Díaz, F. y Hernández, G. (1999). Estrategias docentes para un aprendizaje significativo. México: McGraw Hill.

López, M. (2013). Pensamiento crítico en el aula.

\section{CONCLUSIONES}

Si bien el sistema educativo peruano tiene objetivos claros sobre la mejora de la calidad de enseñanza y lo demuestra mediante sus constantes esfuerzos en la ejecución de proyectos educativos para la formación integral de los alumnos, es necesario que no solo se concentre en resultados a corto y largo plazo que demuestren un buen o alto nivel de rendimiento según lo arrojado por las pruebas internacionales y nacionales. Tiene que centrarse más en la naturaleza de los alumnos como seres individuales.

Las rutas de aprendizaje fueron un gran aporte para el trabajo pedagógico de los docentes peruanos porque ayudó a la reflexión sobre la elaboración de las sesiones de clase tomando en cuenta los procesos de aprendizaje del alumno mediante adecuadas estrategias de enseñanza.

Entre los grandes desafíos que tiene el docente es no perder su interés por su crecimiento profesional mediante actualizaciones y especializaciones, involucrarse más en las tecnologías de la información y el uso de las Tics, y que se mantenga alerta a las necesidades de sus alumnos en cuanto al aspecto afectivo y cognitivo.
Docencia e investigación, 22, 41-60. Madrid, España: CEPE.

Ministerio de Educación (2016). Rutas de Aprendizaje. Lima, Perú: MINEDU.

Parra, C. (1996). Manual de estrategias de enseñanza/aprendizaje. Medellín, Colombia: SENA.

Trahtemberg, L. (2016). Los pendientes de la educación escolar. Recuperado de http://www.trahtemberg.com/articulos/283 $4-1$ o s - p endie n t e s-de-laeducacionescolar.html 